\begin{tabular}{|c|c|c|c|c|c|}
\hline JRL & Vol. 14 & No.1 & Hal. 28-48 & $\begin{array}{c}\text { Jakarta, } \\
\text { Juni 2021 }\end{array}$ & $\begin{array}{r}\text { p-ISSN : 2085.38616 } \\
\text { e-ISSN : 2580-0442 }\end{array}$ \\
\hline
\end{tabular}

\title{
Evaluasi Proses Pre-Treatment Sampah In PLTSa Bantargebang (Studi Kasus Pre-Treatment di PLTSa Bantargebang)
}

\author{
Prasetiyadi \\ Pusat Teknologi Lingkungan Badan Pengkajian dan Penerapan Teknologi \\ Puspiptek Gedung 820 Tanggerang Selatan Banten 15314 \\ E-mail: prasetiyadi@bppt.go.id
}

\begin{abstract}
Abstrak
Pembangkit Listrik Tenaga Sampah (PLTSa) Bantargebang sudah memiliki unit pretreatment sampah, namun kinerjanya masih belum sesuai harapan. Penelitian ini akan mengevaluasi dan memperbaiki metode pre-treatment yang ada agar dapat bekerja lebih optimal sebagai acuan proses pre-treatment sampah umpan PLTSa. Pemilihan teknologi pada pre-treatment sampah dilakukan berdasarkan karakteristik sampah yang ada serta kebutuhan proses dan peralatan untuk mendapatkan sampah terpilah sebagai umpan PLTSa. Hasil evaluasi pemilihan proses dan peralatan pre-treatment eksisting perlu dilakukan penambahan proses dan peralatan, terutama untuk sampah berukuran besar, pembukaan kantong sampah, pemilahan sampah organik, pemilahan sampah lainnya yang dapat dijual dan sampah yang tidak layak bakar, pemilahan logam besi, pemilahan logam non- besi. dan proses sizing
\end{abstract}

Kata kunci : Pre-treatment, MSW, pemilahan sampah, PLTSa

\section{Waste Pre-Treatment Process Evaluation In PLTSa Bantargebang}

\begin{abstract}
The Bantargebang Waste Power Plant (PLTSa) already has a waste pre-treatment unit, but its performance is still not as expected. This study will evaluate and improve the existing pre-treatment method so that it can work more optimally as a reference for the pre-treatment process of PLTSa waste bait. The choice of technology in waste pretreatment is carried out based on the characteristics of existing waste as well as the need for processes and equipment to obtain segregated waste as bait for PLTSa. The results of the evaluation of the existing pre-treatment process and equipment selection need to be added to the process and equipment, especially for large-sized garbage, opening garbage bags, sorting organic waste, sorting other waste that can be sold and waste that is not fit for burning, sorting ferrous metals, sorting metals. non-ferrous. and the sizing process
\end{abstract}

Keywords : Pre-treatment, MSW, Sorting Waste, PLTSa 


\section{PENDAHULUAN}

Sampah di Indonesia pada umumnya masih campur dan belum dilakukan proses pemisahan baik dari sumber maupun di lokasi tempat pembuangan sementara (TPS). Tidak semua sampah bisa dibakar, beberapa jenis sampah tidak bisa terbakar, beberapa lainnya tidak boleh dibakar karena mengandung bahan beracun berbahaya (B3) dan harus dilakukan pemilahan terlebih dahulu. Sejak dioperasikannya Pembangkit Listrik Tenaga Sampah (PLTSa) Bantargebang, PLTSa ini sudah memiliki unit pre-treatment sampah untuk memisahkan material yang tidak boleh masuk kedalam ruang bakar / incinerator. Pada pengoperasiannya PLTSa ini masih ditemukan beberapa beberapa benda keras didalam sisa pembakaran (bottom ash) diantaranya adalah berupa besi dan batu, hal ini menunjukkan bahwa di dalam sampah yang dibakar masih terbawa benda / material yang seharusnya tidak boleh masuk kedalam incinerator. Hal ini menunjukkan proses pre-treatment sampah yang dilakukan belum berjalan sesuai yang diharapkan.

Makalah ini bertujuan mengevaluasi proses pre-treatment sampah PLTSa Bantargebang dan sistim peralatan pre-treatment sampah yang dapat mengolah sampah menjadi bahan bakar PLTSa yang siap digunalan. Dibutuhkan sistim kerja maupun peralatan proses yang harus digunakan agar hasil proses pretreatment sesuai dengan kualitas yang diharapkan.

\section{METODE}

Metode penulisan makalah ini adalah metode deskriptif terhadap kegiatan evaluasi pre-treatment sampah di PLTSa bantargebang saat ini dan evaluasi kondisi serta hasil proses pemilahan untuk dilakukan penyempurnaannya. Pemilihan proses dan kebutuhan peralatan didasarkan pada kondisi/karakteristik sampah yang akan digunakan sebagai bahan bakar PLTSa.

Kriteria pemilihan peralatan proses yang akan dievaluasi dan digunakan dilakukan dengan membandingkan proses / peralatan berdasarkan pada; karakteristik sampah yang tersedia, konstruksi peralatan yang sederhana, mudah mengoperasikannya dan handal.

\section{SAMPAH DAN TEKNOLOGI PENGOLAHAN SAMPAH}

\subsection{Sampah Kota di DKI Jakarta}

Secara praktis sampah kota di DKI Jakarta berdasarkan sumbernya yaitu;.permukiman atau rumah tangga, kantor, pasar tradisional, pusat perniagaan, fasilitas publik, kawasan, sampah lainnya.

Berdasarkan jenisnya, sampah padat dapat digolongkan menjadi 2 (dua) yaitu sebagai berikut :

- Sampah organik, adalah sampah yang dihasilkan dari bahan-bahan hayati. Sampah organik dikenal sebagai sampah basah, sampah ini cepat terdegradasi atau membusuk.

- Sampah non norganik atau anorganik adalah sampah yang 
dihasilkan dari bahan-bahan non hayati, baik berupa produk sintetik maupun hasil proses teknologi pengolahan bahan tambang.
Komposisi dan sifat-sifat sampah juga menggambarkan keanekaragaman aktivitas manusia, komposisi sampah DKI Jakarta ditunjukkan pada tabel 1 berikut:

Tabel 1. Komposisi sampah DKI

\begin{tabular}{|l|c|}
\hline \multicolumn{1}{|c|}{ Komposisi } & Jumlah \\
\hline Sisa Makanan & $55.89 \%$ \\
\hline Kayu Ranting Daun & $4.98 \%$ \\
\hline Kertas & $10.01 \%$ \\
\hline Kertas & $10.55 \%$ \\
\hline Plastik & $1.89 \%$ \\
\hline Logam & $1.89 \%$ \\
\hline Kain Tekstil & $2.50 \%$ \\
\hline Karet Kulit & $1.57 \%$ \\
\hline Kaca & $2.50 \%$ \\
\hline Lainnya & $8.90 \%$ \\
\hline
\end{tabular}

Sumber: SIPSN 2018

Menurut pengamatan di lapangan, densitas sampah di TPA dengan pemadaran konvensional sekitar 0,50 - 0,60 ton/m3 (Anonim, 2018).

Kondisi sampah yang tidak homogen, ini memberikan keuntungan karena tidak dibebani dengan kandungan logam berat, halogen, atau alkali yang terlalu tinggi seperti aliran limbah lainnya misalnya lumpur limbah, limbah elektronik, atau aliran limbah industri berbahaya (Stapf Dieter dkk. 2019)

\subsection{Kondisi Sampah}

Sebagian besar sampah yang dibuang ke tempat pembuangan akhir (TPA) berasal dari sampah rumah tangga. Sampah rumah tangga yang dikumpulkan dari sumbernya sampai di TPA pada umumnya dalam kondisi terbungkus kantong plastik. Di dalam kantong plastik tersebut sampah masih tercampur baik yang organic maupun yang non organic. Kondisi sampah pada umumnya ditunjukkan pada gambar 1. Kandungan air dari sampah rumah tangga ini rata rata 60 \% (Damanhuri, Tri Padmi 2010). 


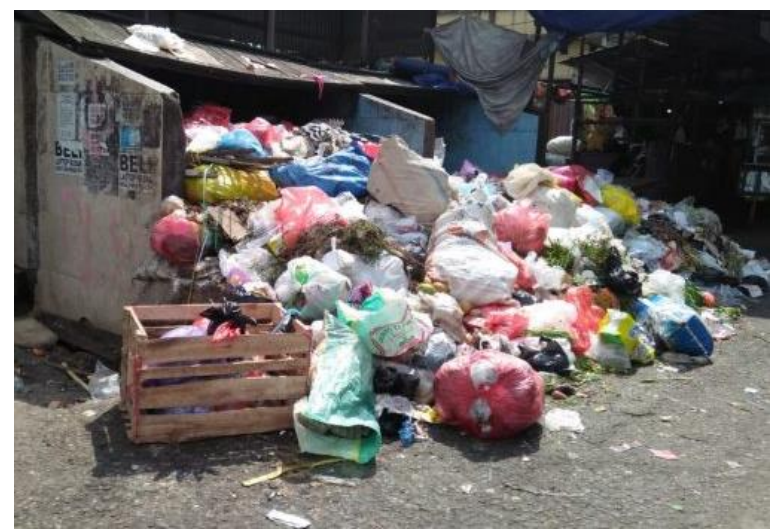

Gambar 1. Sampah di tempat pembuangan sementara

\subsection{Sampah yang tidak boleh masuk insinerator}

Beberapa jenis sampah tidak diperbolehkan masuk kedalam incinerator pembakaran sampah dikarenakan dapat mengganggu kinerja incinerator sebagai berikut:

a. Sampah padat yang tidak bisa atau sulit terbakar diantaranya; besi / logam, batu, puing, keramik, kaca / botol kaca dan tanah. Benda-benda ini selain tidak dapat terbakar dalam incinerator ini bisa masuk ke sela-sela antara grit bagian atas dan bawah sehingga menghambat pergerakan grid tersebut saat mendorong sampah dan dapat merusak grid sistim pengumpanan sampah didalam incinerator. Kasus ini pernah terjadi di PLTSa Bantargebang yang menyebabkan kerusakan grid.

b. Sampah B3 rumah tangga (SB3RT) karena gas buang yang dihasilkan memberatkan kerja peralatan pembersih (Air pollution control / APC). Gas beracun dari pembakaran SB3- RT dapat berupa asam klorida $(\mathrm{HCl})$, formaldehid, dioksin, hexchlorobenzene (HCB), logam berat, $\mathrm{CO}$ dan partikulat lainnya dapat menimbulkan gangguan hormon, dapat masuk ke janin, dan terakumulasi pada tanaman, binatang dan manusia (Iswanto Dkk. 2016) Potensi dampak kesehatan dan lingkungan yang ditimbulkan oleh sampah B3 rumahtangga dipengaruhi oleh kuantitas, karakteristik dan cara penanganannya (Conn,W.D. 1989).

\subsection{Pemanfaatan sampah melalui re deuce re use dan re cycle (3R)}

Pemilahan dan pemanfaatan sampah dengan konsep 3R pada dasarnya sudah dilakukan di kota-kota di Indonesia. Umunmya sebelum sampah sampai ke TPA sejak di tempat sampah rumah tangga dan TPS sampah dilakukan pengurangan / pengambilan oleh 
pemulung atau petugas pengumpul sampah, akan tetapi terbatas pada sampah-sampah yang memiliki nilai ekonomi. Secara jumlah, pengambilankembali sampah yang masih mempunyai nilai ekonomi ini relatif sangat sedikit. ..(Ismail Effendy, Ira Putri Lan Lubis 2018)

Pola penanganan sampah (kondisi eksisting) yang dijalankan masyarakat tidak dapat dilepaskan dari peran sektor informal ini (pemulung dan pengepul sampah) yang memungut beberapa jenis sampah termasuk SB3-RT yang mempunyai nilai jual dan menyerahkan kepada pemanfaat (pabrik). Semakin banyak kuantitas sampah yang dipungut oleh pemulung dan/atau pengepul, maka semakin sedikit jumlah sampah yang dibuang ke lingkungan. (Iswanto Dkk. 2016)

Beberapa bahan yang masih mempunyai nilai ekonomi masih tertinggal didalam tumpukan sampah tersebut dan terbawa ke tempat pembuangan akhir (TPA). Hal ini dikarenakan pemulung hanya mengambil yang mudah dan terlihat saja, sisanya masih terbawa ke TPA..(Ismail Effendy, Ira Putri Lan Lubis 2018)

\subsection{Proses pre-treatment}

Pre-treatment sampah kota adalah proses non-standar yang diterapkan secara luas dengan tujuan prapemilahan dan daur ulang sampah. Produk jenis bahan bakar utama yang berasal dari sampah kota / municipal solid waste (MSW) adalah bahan bakar turunan sampah / refuse-derived fuel (RDF), yang terutama ditujukan untuk tujuan pembakaran. Standar untuk bahan bakar padat yang dipulihkan / Solid Recovery Fuel (SRF), yang merupakan limbah yang disortir dengan lebih ketat. Perlakuan awal pre-treatment sampah melalui penerapan teknologi mekanis dan / atau biologis serta pemilahan manual. Ada dua faktor yang harus dipertimbangkan dalam pretreatmen pemilahan sampah yaitu: nilai ekonomi dari material yang diambil dari sampah dan biaya yang dibutuhkan untuk operasional pre-treatment pemilahan sampah.

Di negara berkembang dengan biaya tenaga kerja yang relative murah pemilahan manual dapat diterapkan. Material yang layak jual dari proses pemilahan ini seperti : botol plastik, besi, dan barang layak jual lainnya menjadi tambahan pendapatan bagi pekerja pemilahan ini. Lain halnya dengan negara maju dimana kebutuhan dasar manusia sudah terpenuhi dan biaya tenaga kerja mahal, maka penanganan sampah menggunakan sistim otomatisasi. (McKinnon D, dkk 2017)

\subsection{Proses Pre-Treatment Eksisting PLTSa Bantargebang}

Proses pre-treatment sampah eksisting PLTSa Bantargebang diawali dengan:

a. Pemilahan awal; dilakukan secara manual untuk membuka bungkusan sampah, memisahkan sampah berukuran besar, ranting, pelepah daun dan pengambilan sampah yang layak jual. 
kemudian sampah terpilah keluar dari ujung Trommel Screen dimasukkan ke konveyor langsung masuk kedalam pengumpan untuk dibawa ke konveyor pemilah Trommel Screen.

c. Pemilahan manual. Di dalam konveyor pemilah, sampah secara manual dipilah oleh pekerja yang diposisikan di sebelah kiri dan kanan sepanjang konveyor. Pada bagian ujung konveyor ini dipasang konveyor pengangkut untuk mengarahkan sampah yang sudah dipilah masuk kedalam bak truk untuk dibawa ke PLTSa untuk dibakar. Trommel Screen yang selanjutnya dibuang ke lokasi penampungan. Sampah kasar

Skema proses pre treatmen eksisting ditunjullan pada gambar 2 berikut.

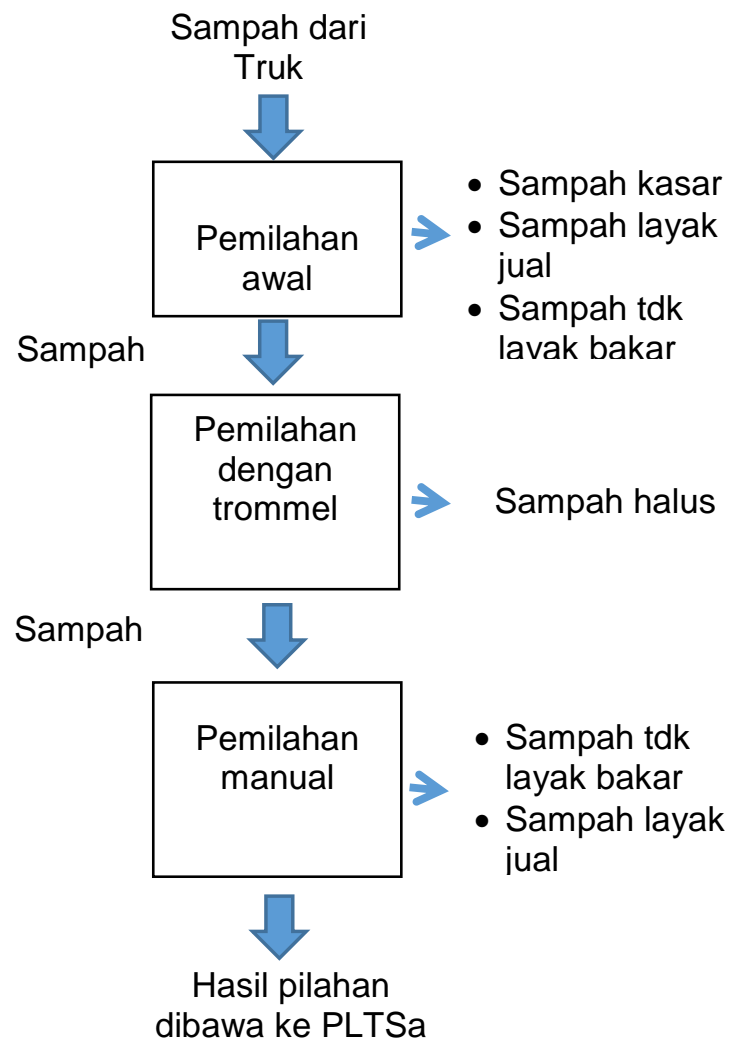

Gambar 2. Proses pre-treatment eksisting PLTSa Bantargebang 
Berdasarkan operasional pemilahan yang dilakukan di unit pre-treatment sampah PLTSa Bantargebang dengan peralatan proses diatas didapat hasil sebagai berikut:

a. Sampah kasar seperti: ranting, pelepahdaun dan sampah berukuran besar lainnya masih belum bisa dimanfaatkan (dipisahkan / terbuang)

b. Kapasitas masih belum mencukupi kebutuhan

c. Benda keras (besi, batu/puing dII) terkadang masih lolos sehingga merusak grit pengumpan pada incinerator

\subsection{Teknologi pemisahan / sortasi bahan}

Pemanfaatan sampah untuk bahan bakar harus melalui proses pemilahan terlebih dahulu karena sampah yang masuk ke TPA masih dalam kondisi tercampur. Teknik pemilahan sampah dapat dikategorikan menjadi dua jenis: pemilahan manual dan pemilahan otomatis. Pada pemilahan otomatis terdapat dua sistim yaitu pemilahan langsung dengan memanfaatkan sifat seperti kerentanan magnetik, konduktivitas dan kepadatan listrik untuk pemisahan media yang berat dengan menerapkan medan eksternal seperti magnet, arus eddy dan gravitasi masing-masing (Gaustad et al., 2012; Mesina et al., 2003; Svoboda, 2004). Pemilahan tidak langsung, menggunakan sensor untuk mendeteksi keberadaan bahan daur ulang di limbah dan biasanya menggunakan mesin atau robot otomatis (S.P. Gundupalli et al.2017). Beberapa teknologi pemilahan ditunjukkan pada tebel berikut:

Tabel 2. Teknologi pemilahan bahan

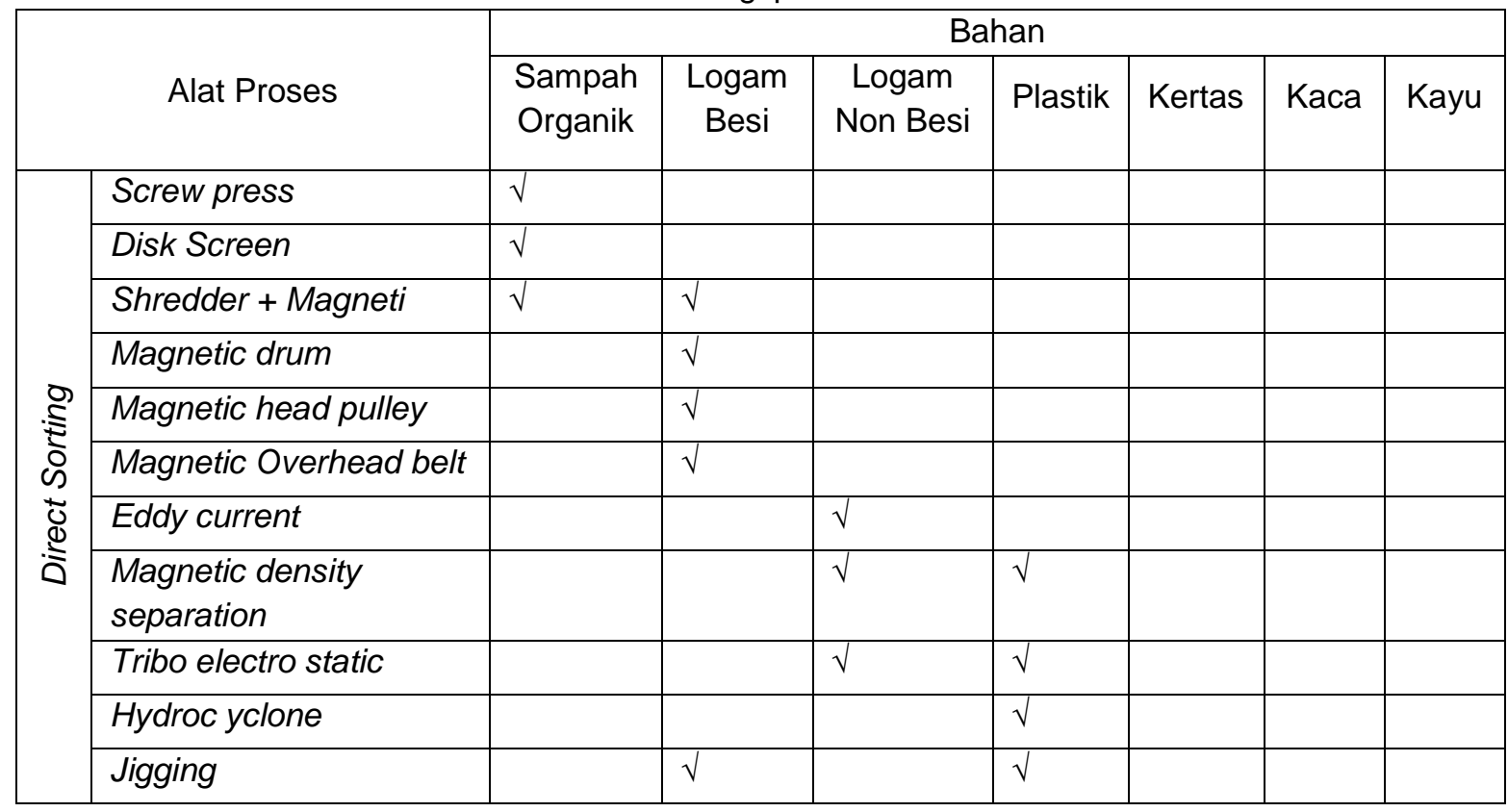




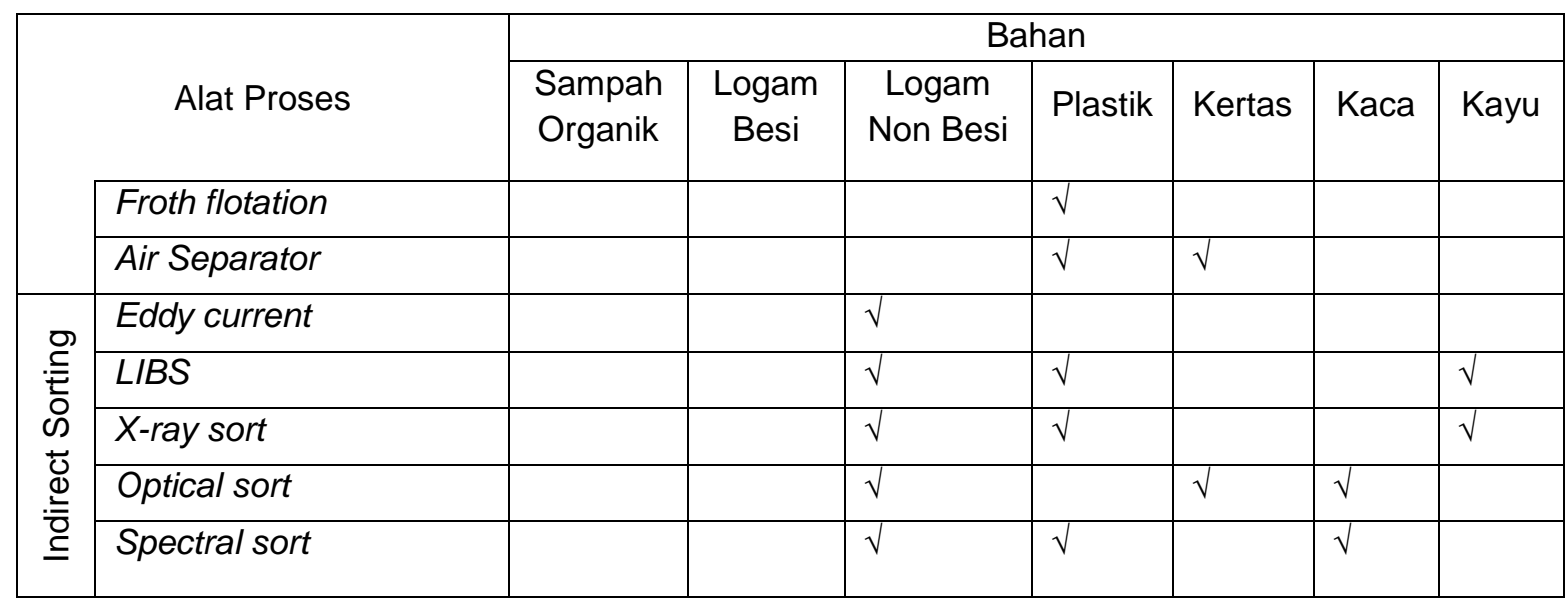

Sumber : Gundupalli, 2017

Menurut Gundapally 2019 "Proses bahan yang terpilah dihancurkan pemilahan sampah adalah proses yang kompleks di mana dimana kegiatan pemilah sampah beroperasi. Penting untuk digaris bawahi bahwa agar pemilahan berkualitas tinggi berhasil, sistem pemilahan sampah harus disesuaikan dengan budaya dan kondisi limbah yang akan diolah". Proses pemilahan yang dilakukan diawali dengan pemilahan antara sampah organic dan non organic. Dari dengan menggunakan shredder, bahan yang sudah hancur tersebut dipisahkan menggunakan magnetic separator untuk memilah logam besi dan menggunakan Eddy Curren untuk memisahkan logam bukan besi, untuk mendapatkan material yang lebih spesifik masing masing output dipilah lagi . Proses tersebut ditunjukkan pada gambar 3 dibawah ini. 


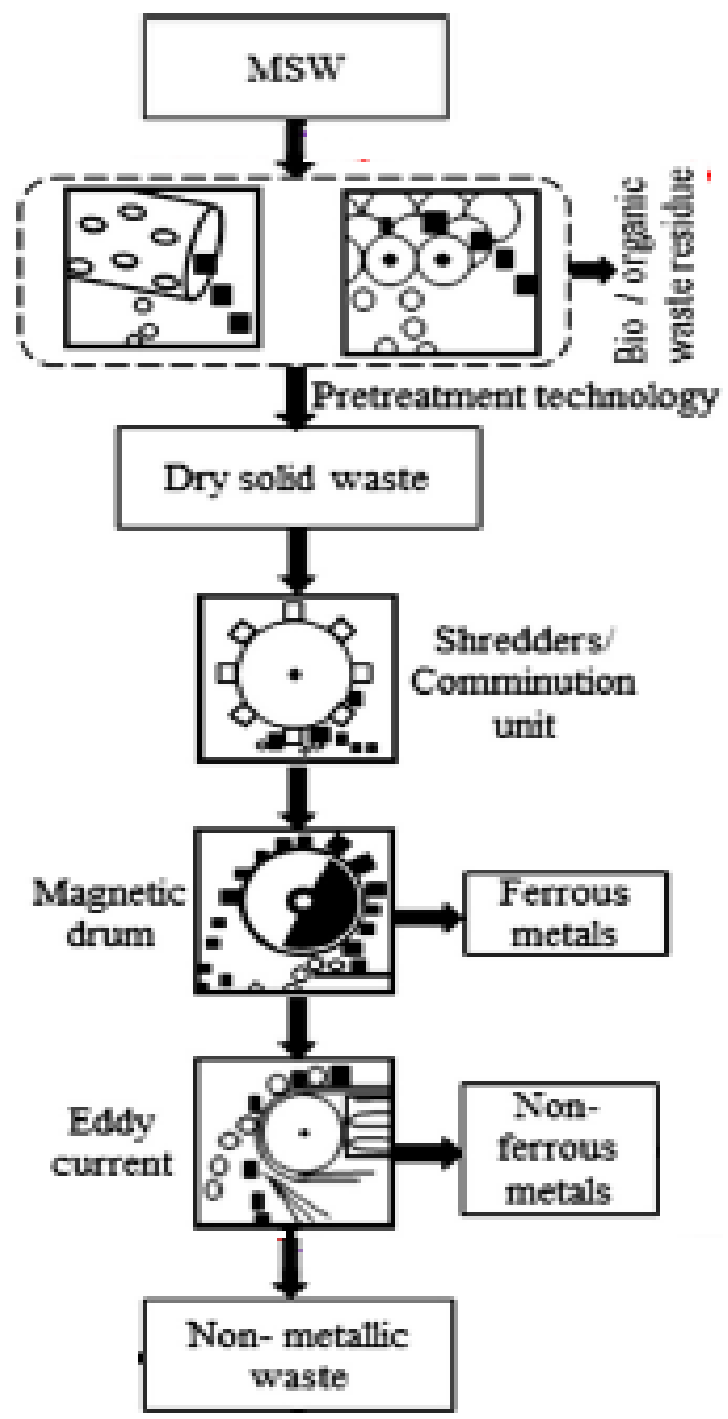

Gambar 3. Proses pemilahan MSW (Gundupalli, 2017)

Hasil studi Regional Solid Waste di Turki oleh JICA 2015 menyebutkan: pemilahan sampah dapat dilakukan secara manual atau mekanik/mesin. Pemilahan manual dapat diterapkan untuk semua jenis bahan, pemilahan manual menjadi pilihan dimana biaya tenaga kerja lebih murah. Pemilahan mekanik memiliki kekhususan sesuai dengan bahan yang akan dipisah misalnya: logam besi, logam non besi, kaca, aluminium dll. Pemilahan mekanik ini membutuhkan investasi awal yang lebih tinggi.

Konfigurasi sistim penyortiran sangat tergantung pada tujuan dan pasar tempat pabrik beroperasi. Di negara maju, pasar didukungan struktur 
berbasis teknologi canggih dalam solusi penyortiran. Dalam hal di negara berkembang lebih realistis menggunakan teknologi sederhana mengingat biaya tenaga kerja tidak mahal. (McKinnon D, Fazakerley J, Hultermans R, 2017). Untuk meningkatkan efisiensi kerja pemilahan, dibutuhkan Bag Breacker / pemecah kantong plastik (KOKUSAI

MS W

Non Compostable Waste

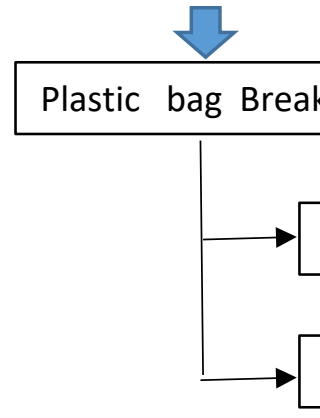

Gambar 4. Proses pemilahan MSW di Turky (JICA 2015)

\section{Magnetic Separator} Ferrous Metal Manual (hand) Sorting $\rightarrow$ PET, Glass, Cullet, ect
KOGYO CO., LTD.). Bag breacker ini menggunakan drum besar yang berputar berlawanan arah untuk membuka kantong secara efisien melepaskan isikantong plastik dan bukan untuk menghancurkan .

Diagram proses pemilahan yang diusulkan ditunjukkan pada gambar 4 berikut :
Stapf Dieter dkk. 2019 dalam "studi kasus pretreatment mekanis, sampah kota (MSW)" menyampaikan produk jenis bahan bakar utama yang berasal dari MSW adalah bahan bakar turunan sampah / refused derived fuel (RDF), yang terutama ditujukan untuk tujuan pembakaran. Standar untuk bahan bakar padat yang dipulihkan atau Solid Recovery Fuel (SRF), yang merupakan limbah yang disortir dengan lebih ketat.

Perlakuan awal sampah menjadi bahan bakar mencakup teknologi mekanis dan / atau biologis serta pemilahan manual. Pada langkah pertama, MSW dihancurkan menggunakan shredder untuk menghasilkan ukuran yang lebih homogen (ukuran kurang dari 150 $\mathrm{mm}$ ) dan untuk meningkatkan densitas curah. Setelah itu, sampah yang berat seperti kaca, batu, dan keramik dibuang menggunakan Air Sifter. Pada langkah ketiga dan keempat, komponen logam besi dan non-besi masing-masing dihilangkan dengan pemisah magnetik overbelt dan pemisah arus eddy. Penghancuran sekunder fraksi yang tersisa menggunakan mesin penghancur untuk mengurangi ukuran partikel hingga ukuran kurang dari $50 \mathrm{~mm}$, sekaligus meningkatkan kerapatan curah. Urutan proses mekanik ini ditunjukkan pada gambar 5 di bawah ini. 


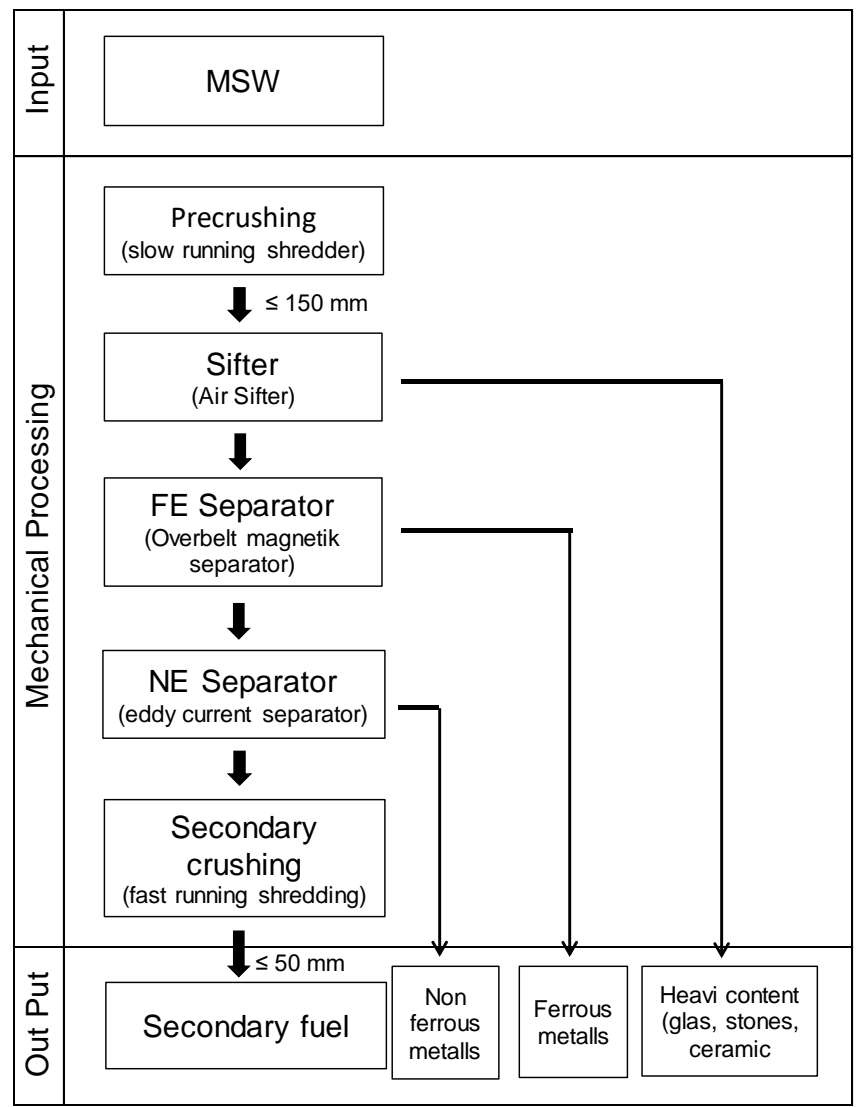

Gambar 5. Proses pemilahan MSW (Stapf Dieter dkk. 2019)

\section{PEMBAHASAN}

\subsection{Kebutuhan jenis proses dalam pre-treatmen sampah}

Pemilahan sampah, selain mencegah terbawanya benda keras yang tidak dapat terbakar dan dapat merusak peralatan incinerator juga untuk mencegah timbulnya pollutan gas buang dari incinerator dari bahan bahan yang beracun (B3) yang ikut masuk kedalam incinerator. Selain itu dibutuhkan juga pembatasan maksimal ukuran sampah (size) agar sampah dengan mudah dapat diumpankan dan masuk ke dalam incinerator. Berdasarkan karakteristik sampah yang ada saat ini, dibutuhkan proses untuk sampah boleh masuk ke damam incinerator sebagai berikut :

Berdasarkan karakteristik sampah yang ada saat ini, dibutuhkan proses untuk sampah boleh masuk ke dalam incinerator yang ditunjukkan pada table 3 berikut 
Tabel 3. Kebutuhan jenis proses pada pre-treatmen sampah

\begin{tabular}{|c|l|l|}
\hline No. & \multicolumn{1}{|c|}{ Jenis sampah } & \multicolumn{1}{|c|}{ Kebutuhan proses } \\
\hline 1 & $\begin{array}{l}\text { Kayu, Ranting, Pelepah daun (sampah } \\
\text { ukuran besar) }\end{array}$ & Pemilahan dan sizing \\
\hline 2 & Sampah dalam kantong & $\begin{array}{l}\text { Mengeluarkan sampah dari } \\
\text { kantong }\end{array}$ \\
\hline 3 & Sisa Makanan (sampah organic) & pemilahan \\
\hline 4 & Kertas & sizing \\
\hline 5 & Kertas & sizing \\
\hline 6 & Plastik & sizing \\
\hline 7 & Logam (besi dan bukan besi) & pemilahan \\
\hline 8 & Kain Tekstil & sizing \\
\hline 9 & Karet Kulit & sizing \\
\hline 10 & Kaca & pemilahan \\
\hline 11 & Lainnya: sampah layak jual, baterai, PVC, & pemilahan \\
\hline
\end{tabular}

Berdasarkan table 3 di atas, untuk proses pre-treatment sampah ini dibutuhkan 3 jenis proses yaitu :

a. Mengeluarkan sampah dari kantong; untuk memudahkan melihat dan memilih bahan mana yang harus dipilah

b. Pemilahan; proses pengambilan / pemisahan bahan yang tidak boleh masuk ke incinerator. Proses pemilaha ini dapat dilakukan dengan dua cara :

- Pemilahan manual ; dimana sampah yang akan dipilah terdiri dari berbagai jenis dan ukuran sehingga tenaga manusia lebih cocok untuk digunakan karena dapat mengenali semua jenis bahan

- Pemilahan mekanik; digunakan sebagai pelengkap jika material yang tidak dikehendaki lolos dari pemilahan manual. Sesuai dengan spesifikasinya pemilah mekanik ini hanya mengenali satu jenis bahan

c. Sizing; proses penyeragaman ukuran agar sampah dapat dimasukkan kedalam incinerator dengan mudah

\subsection{Optimalisasi proses eksisting pre-treatment PLTSa Bantargebang}

Pemilahan sampah eksisting PLTSa Bantargebang masih mempunyai kekurangan yang dapat berpengaruh terhadap kinerja proses pre-treatment itu sendiri maupun kinerja PLTSa Bantargebang diantaranya:

1. Sampah berukuran besar masih dibuang dan belum dimanfaatkan, agar bisa dimanfaatkan sebagai bahan bakar PLTSa maka dibutuhkan proses pencacahan 
agar ukurannya menjadi lebik kecil, dapat dimanfaatkan sebagai bahan bakar dan mudah dimasukkan ke incinerator PLTSa sehingga sampah yang dibuang ke tempet pembuangan akhir (TPA) menjadi berkurang.

2. Proses pembukaan kantong plastik yang masih dilakukan secara manual, ini membutuhkan waktu yang lama sehingga kapasitas menjadi rendah. Untuk meningkatkan kapasitas dibutuhkan peralatan mekanik yang dapat bekerja lebih cepat dan lebih sehat untuk para pekerjanya karena umumnya sampah dalam kantong itu basah dan bau.

3. Masih adanya logam besi yang terbawa masuk kedalam incinerator yang dapat merusak peralatan dan dapat menyebabkan PLTSa berhenti beroperasi. Untuk mengatasi hal ini dibutuhkan proses/alat untuk memilah logam besi yang terbawa di dalam sampah.

4. Masih adanya benda keras (batu/puing) yang terbawa masuk kedalam incinerator yang dapat merusak peralatan dan menyebabkan PLTSa berhenti beroperasi. Untuk mengatasi hal ini dibutuhkan proses/alat untuk memilah keras (batu/puing yang terbawa di dalam sampah.

5. Di dalam tumpukan sampah terkadang terdapat sampah plastik dengan lapisan logam, sampah jenis ini tidak boleh dibakar karena mengandung B3. Pada unit eksisting belum dialakukan pemilahan logam bukan besi. Dibutuhkan pemilah logam bukan besi agar flue gas lebih bersih dan meringankan kerja peralatan pembersih flue gas.

\subsection{Analysis kebutuhan teknologi / peralatan pre- treatmen sampah untuk PLTSa}

Dari table 3 kebutuhan jenis proses pada pre-treatment untuk sampah di atas, teknologi yang dibutuhkan dalam proses pre-treatment ini dipilih berdasarkan jenis sampah, teknologi eksisting dan teknologi yang tersedia, Capex dan Opex serta kemudahan operasi alat sebagai berikut :

1. Pemilakan sampah ukuran besar Pada kondisi eksisting, pemilahan sampah berukuran besar seperti ; kasur, lemari, ranting dan pelepah daun dilakukan secara manual, hasil pemilahan ini dibuang ke TPA. Belum ada teknologi khusus untuk memisahkan sampah jenis ini, sehingga pemilahan sampah berukuran besar ini tetap. Agar sampah ini dapat dimanfaatkan dilakukan proses sizing agar ukurannya menjadi lebih kecil dan dapat diumpankan ke incinerator.

2. Proses pembukaan kantong plastik

Salah satu kendala yang menyebabkan kapasitas pretreatment eksisting rendah adalan proses pembukaan kantong sampah masih dilakukan secara manual kerena sebagian besar 
sampah terbungkus dalam kantong plastic,.., untuk membuka / kantong plastic ini dibutuhkan mesin agar proses bisa berlangsung lebih cepat dan lebih aman untuk pekerjanya. Teknologi yang dapat digunakan untuk proses ini ditunjukkan pada tabel 4 berikut :

Tabel 4. Pemilihan teknologi pembuka kantong sampah

\begin{tabular}{|c|l|c|c|l|}
\hline No. & Teknologi/Alat & Hasil proses & $\begin{array}{c}\text { Capex } \\
\text { dan Opex }\end{array}$ & \multicolumn{1}{c|}{ Catatan } \\
\hline 1 & Crusher & $\begin{array}{l}\text { Kantong dan } \\
\text { isinya hancur }\end{array}$ & tinggi & $\begin{array}{l}\text { Kapasitas tinggi } \\
\text { Dipilih jika tenaga kerja mahal } \\
\text { dan seluruh proses dilakukan } \\
\text { secara mekanik }\end{array}$ \\
\hline 2 & Bag Breaker & $\begin{array}{l}\text { Kantong sobek, } \\
\text { isi kantong utuh }\end{array}$ & rendah & $\begin{array}{l}\text { Kapasitas tinggi } \\
\text { Dipilih jika tenaga kerja murah } \\
\text { dan proses tidak semua mekanik }\end{array}$ \\
\hline 3 & $\begin{array}{l}\text { Kondisi } \\
\text { eksisting } \\
\text { (manual) }\end{array}$ & $\begin{array}{l}\text { Kantong sobek, } \\
\text { isi kantong utuh }\end{array}$ & rendah & Kapasitas rendah \\
\hline
\end{tabular}

Untuk proses pembukaan kantong dipilih teknologi/alat bag braker karena di Indonesia tenaga kerja masih termasuk murah dibanding dengan di negara maju. Penempatan Bag Breaker ini sebelum pemilahan sampah tidak layak bakar seperti ditunjukkan pada gambar 4 .

3. Pemilahan sampah organic

Sisa makanan atau sampah organic ini biasanya berbentuk remah yang halus sehingga pemisahannya dengan disaring.
Sampah organic ini dipisahkan karena kandungan airnya tinggi dan jika dimakar akan menghasilkan abu dengan jumlah tang banyak sehingga lebih cocok untuk dijadikan kompos. Teknologi yang dapat digunakan untuk memisahkan adalah: trommel screen (gambar 2) dan Disk Screen (tabel 2). Perbandingan teknologi yang dapat digunakan untuk proses pemilahan sampah organik ini ditunjukkan pada tabel 5 berikut : 
Tabel 5. Pemilihan teknologi pemilahan sampah organik

\begin{tabular}{|c|l|c|c|}
\hline No. & Teknologi/Alat & $\begin{array}{c}\text { Capex } \\
\text { dan } \\
\text { Opex }\end{array}$ & Cara kerja/kondisi operasi \\
\hline 1 & Trommel Srceen & rendah & $\begin{array}{l}\text { Dapat digunakan untuk sampah } \\
\text { dengan kadar air tinggi }\end{array}$ \\
\hline 2 & Disk Skreen & tinggi & digunakan untuk sampah kering \\
\hline 3 & $\begin{array}{l}\text { Kondisi eksisting } \\
\text { Trommel }\end{array}$ & rendah & $\begin{array}{l}\text { Dapat digunakan untuk sampah } \\
\text { dengan kadar air tinggi }\end{array}$ \\
\hline
\end{tabular}

Berdasarkan perbandingan diatas untuk pemilahan sampah organic dipilih menggunakan teknologi/alat Trommel Screen untuk memilah sampah organic karena selain lebih murah juga cocok untuk sampah di Indonesia yang mempunyai kadar air tinggi. Kondisi eksisting pemisahan sampah organic menggunakan trommel screen dan selama ini dapat berfungsi dengan baik. Trommel Screen ini diletakkan

setelah proses pembukaan kantong dengan bag breaker.

4. Pemilahan logam besi

Teknologi pemilahan logam besi seperti ditunjukkan pada tabel 2 , gambar 3 gambar 4 dan gambar 5 yaitu menggunakan magnetic kecuali teknologi Jigging yang menggunakan getaran, teknologi pemilahan logam besi ditunjukkan pada tabel 6 di bawah ini.

Tabel 6. Pemilihan teknologi pemilahan logam besi

\begin{tabular}{|c|l|c|l|}
\hline No. & Teknologi/Alat & $\begin{array}{c}\text { Capex } \\
\text { dan Opex }\end{array}$ & \multicolumn{1}{c|}{ Cara kerja/kondisi operasi } \\
\hline 1 & $\begin{array}{l}\text { Shredder }+ \\
\text { Magneti }\end{array}$ & tinggi & $\begin{array}{l}\text { Semua material dihancurkan dulu } \\
\text { dengan shredder, cocok untuk } \\
\text { total penanganan mekanik } \\
\text { dimana biaya tenaga kerja tinggi }\end{array}$ \\
\hline 2 & Magnetic drum & rendah & $\begin{array}{l}\text { Bidang kontak kecil, terpisah } \\
\text { dengan konveyor sampah }\end{array}$ \\
\hline 3 & $\begin{array}{l}\text { Magnetic head } \\
\text { pulley }\end{array}$ & rendah & $\begin{array}{l}\text { Bidang kontak lebih luas, } \\
\text { menyatu dengan konveror } \\
\text { sampah }\end{array}$ \\
\hline 5 & Overhead belt & rendah & $\begin{array}{l}\text { Bidang kontak lebih luas terpisah } \\
\text { dengan konveyor sampah }\end{array}$ \\
\hline
\end{tabular}




\begin{tabular}{|c|l|l|l|}
\hline 6 & $\begin{array}{l}\text { Kondisi } \\
\text { eksisting } \\
\text { (Manual) }\end{array}$ & rendah & $\begin{array}{l}\text { Beberapa logam besi tidak } \\
\text { terambil (lolos) }\end{array}$ \\
\hline
\end{tabular}

Dari 6 alternatif teknologi terdapat 2 teknologi pemilah logam besi sistim magnet (magnetic separator) dengan biaya Capex \& Opex rendah dan mempunyai bidang kontak yang luas yaitu Magnetic head pulley dan Magnetic over head belt. Pada Magnetic head pulley posisi magnet diletakkan pada pulley bagian ujung konveyor, sedangkan pada Magnetic over head belt penempatan system magnet ini dapat di geser-geser sepanjang konveyor pemilah sehingga lebih leluasa dalam menentukan tempat penampungan logam besi terpilah sehingga untuk proses pemilahan logam besi ini dipilih teknologi magnetic separator dengan system Magnetic Overhead belt.

5. Pemilahan logam non ferro

Didalam komposisi sampah terdapat juga plastic "multi layer" (plastik yang dilapisi almuniaum) seperti bungkus kopi, permen dll. Teknik pemilahan sampah logam non ferro termasuk dalam teknologi/peralatan otomatis yang dapat dikategorikan menjadi dua jenis yaitu pemilahan langsung dan pemilahan tidak langsung:

$\checkmark$ Teknologi pemilahan langsung pada proses pemilahan logam non ferro memanfaatkan sifat material seperti kerentanan magnetis, konduktivitas dan kepadatan listrik untuk pemisahan media yang berat oleh medan magnet, arus eddy dan gravitasi (Gaustad et al., 2012; Mesina et al., 2003; Svoboda,2004).

$\checkmark$ Pemilahan tidak langsung, menggunakan sensor untuk mendeteksi keberadaan bahan daur ulang di limbah dalam jumlah besar yang diikuti dengan pemilahan menggunakan berbagai peralatan otomatis (sistim robot) dalam penyortiran tidak langsung ini. Teknologi pemilahan tidak langsung seperti; teknologi eddy current, LIBS, X-ray sort, Optical sort dan Spectral sort cocok untuk digunakan pada proses pemilahan sampah secara full mekanik dengan system otomatis, akan tetapi biaya Capex dan Opexnya tinggi.

Teknologi yang banyak digunakan untuk pemilahan logam non ferro adalah teknologi dengan sistim Direct Sorting seperti ditunjukkan pada tabel 7 . 
Tabel 7. Teknologi pemilahan logam non ferro

\begin{tabular}{|c|l|l|l|}
\hline No. & Teknologi/Alat & $\begin{array}{l}\text { Capex } \\
\text { dan Opex }\end{array}$ & Cara kerja/kondisi operasi \\
\hline 1 & Eddy current & rendah & $\begin{array}{l}\text { Magnet eksternal arus Eddy, bekerja berlawanan } \\
\text { dengan magnit atau mengusir logam campuran. } \\
\text { (logam non ferro) }\end{array}$ \\
\hline 2 & $\begin{array}{l}\text { Magnetic } \\
\text { density } \\
\text { separation }\end{array}$ & tinggi & $\begin{array}{l}\text { memanfaatkan cairan magnet (ferrofluid) sebagai } \\
\text { media pemisah, tidak cocok untuk pengolahan } \\
\text { sampah }\end{array}$ \\
\hline 3 & $\begin{array}{l}\text { Tribo electro } \\
\text { static }\end{array}$ & tinggi & $\begin{array}{l}\text { Memanfaatkan medan listrik untuk menyortir } \\
\text { melalui gesekan elektrifikasi yang dilewatkan } \\
\text { melalui ruang tribocharging }\end{array}$ \\
\hline 4 & $\begin{array}{l}\text { Kondisi } \\
\text { eksisting } \\
\text { (Manual) }\end{array}$ & rendah & Beberapa logam bukan besi tidak terambil (lolos) \\
\hline
\end{tabular}

Dari ketiga teknologi direct sorting untuk logam non ferro dipilih teknologi Eddy Current karena selain biaya Capex dan Opex nya rendah juga prosesnya sederhana. Proses pemilahan logam non ferro ini biasanya diletakkan pada bagian akhir proses pemilahan.

6. Pemilahan sampah lainnya

Teknologi untuk memisahkan sampah lainnya seperti : botol plastik (sampah layak jual), puing dan batu, kaca sampah elektronik dill. telah tersedia baik yang menggunakan pemilahan mekanik otomatik langsung (direct sorting) maupun dengan pemisahan tidak langsung (indirect sorting). Pada penggunaan teknologi pemilahan mekanik membutuhkan biaya investasi peralatan yang tinggi. $\mathrm{Di}$ negara-negara maju proses pemilahan ini masih banyak yang menggunakan cara manual kerena manusia lebih fleksibel dalam memilih jenis sampah yang harus dipisahkan. Berdasarkan hal ini untuk pemilahan sampah lainnya digunakan cara manual, pemilahan dilakukan diatas ban berjalan (konveyor). Pada kondisi eksisting masih terdapat batu, puing atau benda keras lainnya yang belum terambil (lolos) dalam pemilahan manual ini. Untuk menghindari hal ini perlu ditambahkan "air sifter" pada bagian ujung konveyor pemilah. Peletakan urutan proses ini sebaiknya ditempatkan setelah pemilahan sampah organic karena setelah sampah organik dipisahkan volume dan bau berkurang.

7. Proses sizing

Pada kondisi eksisting belum dilakukan proses sizing terhadap 
sampah yang akan dimasukkan ke incinerator, hal ini terkadang menyebabkan terjadinya kendala pada sistim pengumpanan sampah dimana sampah kain atau tali yang panjang melilit dibagian pintu hopper. Dibutuhkan alat untuk memotong sampah agar memudahkan pengumpanan sampah kedalam incinerator PLTSa. Teknologi / alat yang digunakan untuk proses ini adalah mesin crusher. Penempatan mesin ini di akhir proses, hal ini bertujuan agar sampah yang akan dihancurkan /dipotong sudah bersih dari benda keras yang dapat merusak mesin crusher. Dari proses ini sampah / bahan siap untuk dikirim ke bunker PLTSa.

Dari hasil analisa dibutuhkan beberapa proses dan peralatan proses untuk pre-treatment sampah PLTSa yang meliputi ; pemilahan manual untuk memisahkan sampah ukuran besar, pembukaan kantong sampah, pemilahan sampah organic, pemilahan manual sampah lainnya, pemilahan logam besi, pamilahan logam non besi dan sizing Selain peralatan untuk rangkaian proses ini dibutuhkan juga alat bantu (konveyor, loader / excavator) untuk memudahkan transportasi / pemindahan bahan dari proses sebelumnya ke proses berikutnya. Secara skematik analisa proses menhgasilkan usulan rangkaian proses pre-treatment sampah PLTSa seperti ditunjukkan pada gambar 6 berikut : 


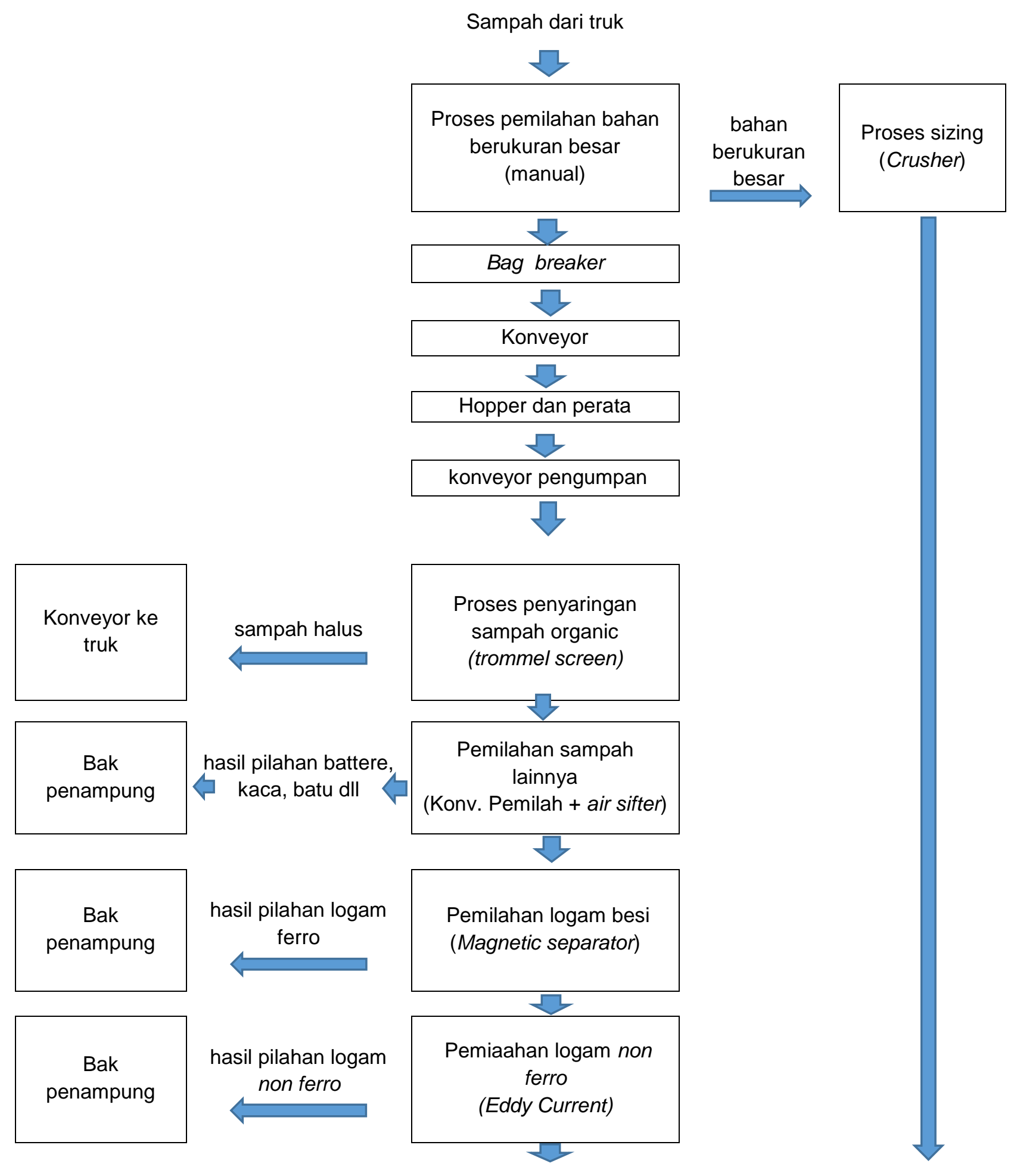




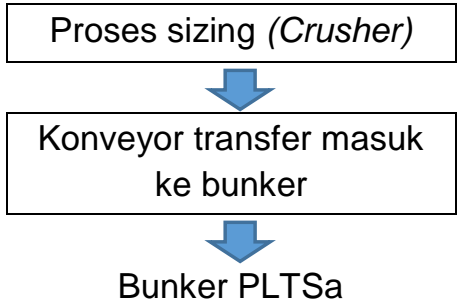

Gambar 6. Usulan proses dan peralatan pre-treatment sampah untuk umpan PLTSa

\section{KESIMPULAN DAN SARAN}

\subsection{KESIMPULAN}

Pre-treatment sampah eksisting PLTSa Bantargebang masih mempunyai kekurangan yang dapat berpengaruh kinerja proses pretreatment itu sendiri maupun kinerja PLTSa Bantargebang diantaranya: sampah berukuran besar belum dimanfaatkan, proses pembukaan kantong plastic dilakukan secara manual dan waktu yang lama, masih adanya batu, puing, logam besi, logam bukan besi yang terbawa masuk kedalam incinerator.

Untuk menyempurnakan proses pretreatment eksisting, telah dilakukan analisa kebutuhan proses dan peralatan pre-treatment sampah untuk umpan PLTSa sebagai berikut :

1. Pemilahan sampah ukuran besar secara manual, dan dilakukan proses sizing agar dapat diumpankan ke incinerator.

2. Proses pembukaan kantong plastik menggunakan bag braker.

3. Pemilahan sampah organik menggunakan Trommel Screen.

4. Pemilahan logam besi dengan system Magnetic Overhead belt.

5. Pemilahan logam non ferro teknologi Eddy Current
6. Pemilahan sampah lainnya digunakan cara manual diatas ban berjalan (konveyor) dengan penambahan "air sifter" pada bagian ujung konveyor pemilah .

7. Proses sizing untuk memotong sampah menggunakan mesin crusher

Selain peralatan proses utama, dibutuhkan juga peralatan pendukung (konveyor, loader / excavator) untuk memudahkan transportasi / pemindahan bahan dari proses sebelumnya ke proses berikutnya.

\subsection{SARAN}

Untuk menurunkan kandungan air dari sampah segar yang diolah dapat dilakukan dengan menambah proses bio drying. Dengan proses dan peralatan yang sama dapat dimanfaatkan sampah dari hasil maining (sampah lama yang sudah ditimbun) sebagai bahan bakar PLTSa

\section{DAFTAR PUSTAKA}

Amonimous. 2018 "Sistim Informasi Pengelolaan Sampah Nasional (SIPSN) 2018" Direktorat 
Pengelolaan Sampah, Limbah dan B3

Conn, W.D., 1989. "Managing Household Hazardous Waste". Journal of the American Planning Association, 55:192-203

Damanhuri, Tri Padmi 2010 "Diktat Kuliah TL-3104" (Versi 2010) Program Studi Teknik Lingkungan Fakultas Teknik Sipil dan Lingkungan INSTITUT TEKNOLOGI BANDUNG

Gaustad, G., Olivetti, E., Kirchain, R., 2012. "Improving aluminum recycling: a survey of sorting and impurity removal technologies". Resour. Conserv. Recycl. 58, 7987

GIZ_WasteToEnergy_Guidelines_201

7 "Waste-to-Energy Options in Municipal Solid Waste Management" A Guide for Decision Makers in Developing and Emerging Countries 2017

Ismail Effendy, Ira Putri Lan Lubis (2018) "Manajemen Tata Kelola Sampah Di Perkotaan ( Studi Kasus Di Kota Medan )". Fakultas Kesehatan Masyarakat Institut Kesehatan Helvetia.

Iswanto Dkk. 2016 "Timbulan Sampah

B3 Rumahtangga Dan Potensi

Dampak Kesehatan Lingkungan Di Kabupaten Sleman, Yogyakarta". Jurnal MANUSIA DAN LINGKUNGAN, Vol. 23, No.2, Juli 2016: 179-188

Japan International Cooperation Agency (JICA) 2015 "The Study on Regional Solid Waste Management for Adana-Mersin in the Republic of Turkey" Annex 8
Design of Separate Collection system KOKUSAI KOGYO CO., LTD.

Kementerian Lingkungan Hidup dan Kehutanan Jl. D.I. Panjaitan Kav. 24 Kebon Nanas, Jakarta Timur

McKinnon D, Fazakerley J, Hultermans R, (2017). "Waste sorting plants - extracting value from waste" Vienna, Austria: International Solid Waste Association (ISWA)

Mesina, M.B., De Jong, T.P.R., Dalmijn, W.L., 2003. "Improvements in separation of non-ferrous scrap metals using an electromagnetic sensor" Phys. Sep. Sci. Eng. 12 (2), 87-101.

S.P. Gundupalli et al. (2017) "A review on automated sorting of source-separated municipal solid waste for recycling". Journal Waste Management 56-74 (2017)homepage: www.elsevier.com/ locate/wasman

Stapf Dieter dkk. 2019 "Pretreatment of municipal solid waste (MSW) for gasification (Biomass pretreatment for bioenergy - Case study 3)". IEA Bioenergy, Februari 2019.

https://www.researchgate.net/publ ication/331843209 [Online, diunduh pada 8 Desember 2020]

Svoboda, J., 2004. "Magnetic Techniques for the Treatment of Materials. Springer". Kluwer Academic; 2004th edition 